\title{
Kajian Perbandingan Kuat Tumpu Baut Sejajar Serat Hasil Uji Eksperimental dan SNI 7973:2013
}

\author{
NESSA VALIANTINE DIREDJA \\ Institut Teknologi Nasional Bandung \\ Email: nessa.valiantine@itenas.ac.id
}

\begin{abstract}
ABSTRAK
Sambungan merupakan salah satu metode yang dapat digunakan untuk mendapatkan dimensi kayu sesuai kebutuhan karena terbatasnya ukuran kayu. Kuat tumpu pasak pada kayu diperlukan pada perhitungan sambungan kayu. Melalui persamaan SNI 7973:2013 kuat tumpu pasak pada kayu dapat ditentukan berdasarkan berat jenis kayu, arah serat dan diameter pasak. Pada penelitian ini dilakukan pengujian eksperimental kuat tumpu baut sejajar serat pada 3 jenis kayu yang dibandingkan dengan analisis teoritis berdasarkan SNI 7973:2013. Pengujian dilakukan berdasarkan ASTM D5764-97a dengan menggunakan baut berdiameter $10 \mathrm{~mm}$. Hasil penelitian menunjukan bahwa kuat tumpu baut hasil pengujian eksperimental nilainya lebih kecil apabila dibandingkan dengan persamaan berdasarkan SNI 7973:2013. Persen beda yang didapatkan adalah sebesar 52,57\% untuk kayu Sengon; 18,01\% untuk kayu Akasia dan 4,80\% untuk kayu Meranti.
\end{abstract}

Kata kunci: kuat tumpu pasak, sejajar serat, SNI 7973:2013.

\begin{abstract}
Connection is one of method that can be used to get the dimension of wood as needed because the limited size of wood. Bearing strength of wood is required on timber connection calculation. According to SNI 7973:2013, bearing strength can be determined based on the spesific gravity, direction of grain and diameter of fasteners. This study compares the value of bearing strength parrallel to wood grain on 3 different types of wood obtain from experimental test with theoritically generated valued based on SNI 7973:2013. Experimental test is done based on ASTM D5764-97a using $10 \mathrm{~mm}$ diameter bolts. The result showed that the bearing strength of experimental test has less value compared with the equation based on the SNI 7973:2013. The percentage differences are 52,57\% for Sengon; 18,01\% for Acasia and 4,80\% for Meranti.
\end{abstract}

Keywords: dowel bearing strength, parallel to grain, SNI 7973:2013. 


\section{PENDAHULUAN}

Kayu merupakan bahan konstruksi yang paling disukai oleh masyarakat Indonesia karena sifatnya yang ringan dan mudah dalam pengerjaan. Kayu memiliki sifat yang berbeda bergantung kepada jenisnya, salah satu faktor yang mempengaruhi kekuatan kayu adalah berat jenis, kadar air, lama pembebanan, jenis kayu juga besar serta lokasi cacat kayu. Umumnya semakin besar berat jenis suatu kayu maka semakin besar pula kekuatannya. Selain itu, kadar air juga memiliki pengaruh terhadap kekuatan mekanik kayu, semakin kecil kadar air dari suatu kayu semakin meningkat sifat mekanik kayu tersebut (Rammer, D. R. \& Winistorfer, S. G., 1999). Pengaruh kadar air terhadap kekuatan kayu dapat dilihat pada Gambar 1.

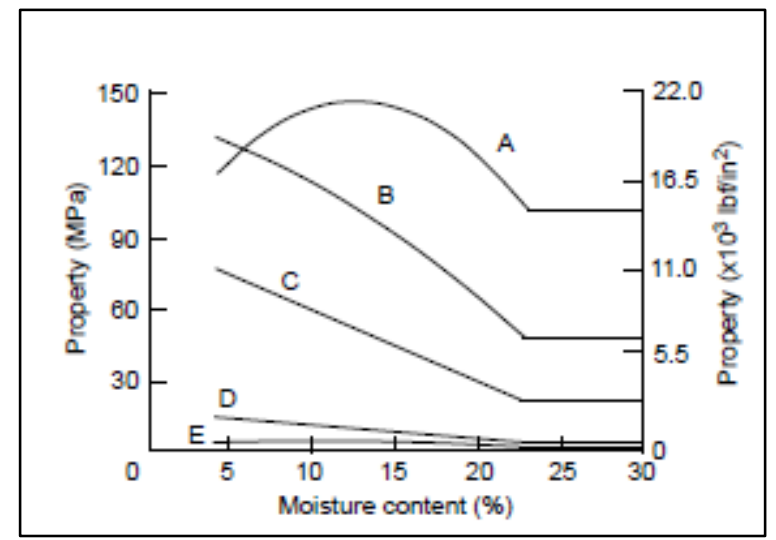

Gambar 1. Pengaruh kadar air pada kekuatan kayu. A, kuat tarik sejajar serat; B, kuat lentur; C, kuat tekan sejajar serat; D, kuat tekan tegak lurus serat; E, kuat tarik tegak lurus serat. (Sumber: Forest Product Laboratory, 1999)

Kayu yang merupakan bahan murni dari alam membuat material ini sangat terbatas dalam segi ukuran yang diperlukan untuk konstruksi. Keterbatasan ini membuat kayu membutuhkan sambungan untuk memenuhi dimensi yang diperlukan. Umumnya sambungan merupakan bagian struktur yang rentan mengalami kegagalan. Pada sambungan kayu terdapat beberapa moda kegagalan, salah satunya adalah kegagalan tumpu pada komponen utama atau komponen samping maupun kegagalan pada alat sambung. Penelitian ini bertujuan untuk membandingkan kekuatan tumpu baut dengan menggunakan baut berdiameter $10 \mathrm{~mm}$ pada 3 jenis kayu yaitu kayu Sengon, kayu Akasia dan kayu Meranti berdasarkan pengujian eksperimental yang dibandingkan dengan analisis berdasarkan persamaan yang terdapat pada Badan Standardisasi Nasional (2013).

\section{TINJAUAN PUSTAKA}

Kayu merupakan material ortotropik sehingga membuat kayu memiliki sifat mekanik yang unik pada ketiga sumbu aksisnya yaitu, sumbu tangensial, radial dan longitudinal. Sifat mekanik kayu juga bergantung pada jenisnya. Sifat mekanik kayu yang umumnya diperhitungkan dalam desain adalah kuat geser, kuat lentur, kuat tekan, kuat tumpu dan kuat tarik.

Kuat tumpu pasak adalah salah satu parameter yang diperlukan pada perhitungan sambungan kayu yang merupakan kekuatan maksimum kayu pada sekeliling lubang yang dibebani pasak. Berdasarkan Badan Standardisasi Nasional (2013), besar kuat tumpu pasak kayu bergantung pada berat jenis kayu, arah serat dan diameter pasak yang digunakan. Pasak atau alat pengencang yang biasanya digunakan di Indonesia adalah paku, sekrup dan baut. Baut sangat 
umum digunakan pada sambungan kayu karena memiliki kelebihan yaitu mudah dalam pemasangan, ekonomis serta mampu menahan beban besar. Baut dapat digunakan pada sambungan kayu geser tunggal maupun sambungan geser ganda. Kekuatan sambungan menggunakan baut ditentukan oleh beberapa parameter yaitu kuat leleh lentur dari pengencang, kuat tumpu atau kuat geser dari komponen kayu dan geometri sambungan itu sendiri (Breyer, D. E. et al., 2015).

Penelitian yang dilakukan oleh Thomas L Wilkinson (1991) menyebutkan bahwa kekuatan tumpu baut sejajar serat bergantung pada berat jenis, kuat tumpu baut tegak lurus serat bergantung pada berat jenis dan diameter baut, sedangkan kuat tumpu pasak menggunakan paku bergantung pada berat jenis saja.

Pada sambungan kayu, kegagalan tumpu pasak pada komponen utama maupun komponen samping umumnya merupakan kegagalan yang paling sering terjadi. Berdasarkan persamaan dari Badan Standardisasi Nasional (2013), kuat tumpu pasak kayu sejajar serat dapat dihitung menggunakan Persamaan 1 dan Persamaan 2.

$$
\begin{aligned}
& F_{e}=70 G \text { untuk } D \leq 6,35 \mathrm{~mm} \\
& F_{e}=100 G^{1,84} \text { untuk } D>6,35 \mathrm{~mm}
\end{aligned}
$$

halmana:

$\begin{array}{ll}F_{e} & =\text { kuat tumpu pasak }[\mathrm{MPa}] \\ G & =\text { berat jenis kayu }\left[\mathrm{gr} / \mathrm{cm}^{3}\right] \\ D & =\text { diameter pasak }[\mathrm{mm}] .\end{array}$

Untuk mengetahui kapasitas kekuatan tumpu yang terjadi digunakan pendekatan European Yield Model (EYM). Teori umum mengenai teori leleh adalah mengasumsikan mekanisme plastisitas pada alat sambung dan sambungan kayu (Aune, P. \& Mallory, M. P., 1986). Kuat tumpu $\left(F_{e}\right)$ pada kondisi $5 \%$ offset dapat diperoleh dengan cara membagi beban leleh pada saat $5 \%$ offset $\left(P_{5 \%}\right)$ dengan diameter baut dan tebal benda uji. Penentuan titik leleh berdasarkan teori EYM dapat dilihat pada Gambar 2.

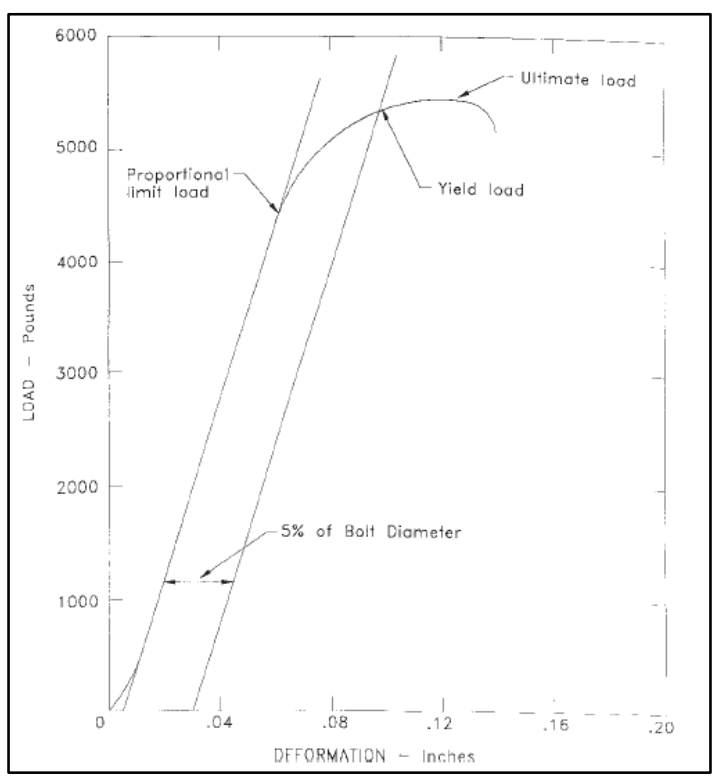

Gambar 2. Penentuan titik leleh berdasarkan teori EYM

(Sumber: ASTM D5764-97a, 1997)

Reka Racana - 42 


\section{METODOLOGI PENELITIAN}

Penelitian ini dilakukan dengan dua metode, yaitu dengan cara analisis dan berdasarkan hasil pengujian eksperimental. Pada pengujian eksperimental, pengujian dilakukan menggunakan Universal Testing Machine (UTM), metode tes kuat tumpu pasak didasarkan pada ASTM D5764-97a (1997). ASTM ini menyediakan prosedur untuk pengujian kekuatan tumpu pasak baik untuk kayu ataupun produk yang berbasis kayu. Dalam pengujian kuat tumpu pasak, terdapat 2 metode yang dapat digunakan, yaitu metode lubang penuh dan metode setengah lubang. Pada penelitian ini metode yang digunakan adalah metode setengah lubang. Pengujian dengan konfigurasi lubang penuh dapat dilaksanakan apabila benda uji cenderung untuk mengalami splitsebelum pengujian selesai. Konfigurasi benda uji-setengah lubang ditunjukkan pada Gambar 3.

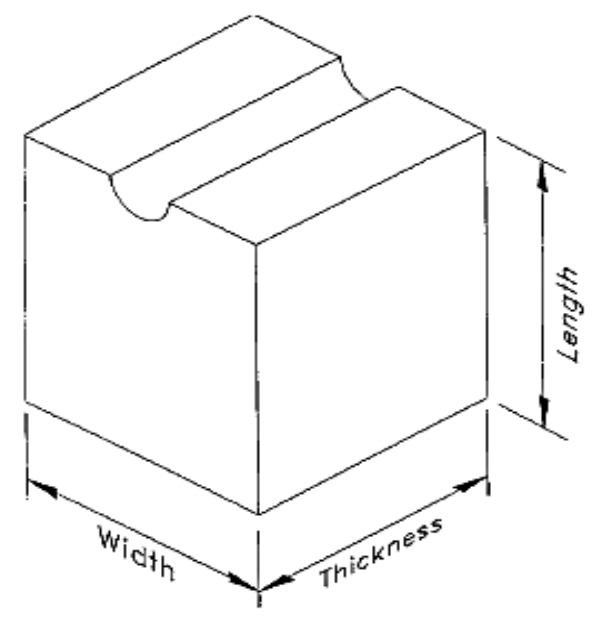

Gambar 3. Konfigurasi benda uji-setengah lubang

(Sumber: ASTM D5764-97a, 1997)

Prosedur pengujian kuat tumpu pasak dengan metode setengah lubang dilakukan dengan cara sebagai berikut:

1. Mula-mula masing-masing benda uji diukur dan ditimbang untuk mengetahui berat jenisnya. Berat jenis ini diperlukan sebagai parameter pada perhitungan analisis teoritis.

2. Pengujian kuat tumpu dilakukan menggunakan mesin UTM dengan cara meletakkan baut berdiameter $10 \mathrm{~mm}$ diatas setengah lubang pada benda uji.

3. Benda uji diletakkan pada mesin UTM dan mulai dilakukan pengujian tekan.

4. Beban tekan kemudian diberikan secara merata sepanjang baut. Peralihan yang dialami oleh baut bisa diwakili dengan pergerakan moveable crosshead pada UTM. Kecepatan yang diberikan adalah $1 \mathrm{~mm} / \mathrm{menit}$.

5. Pengujian berhenti pada saat beban maksimum sudah dicapai atau baut telah tertanam ke dalam kayu (Gambar 4). 


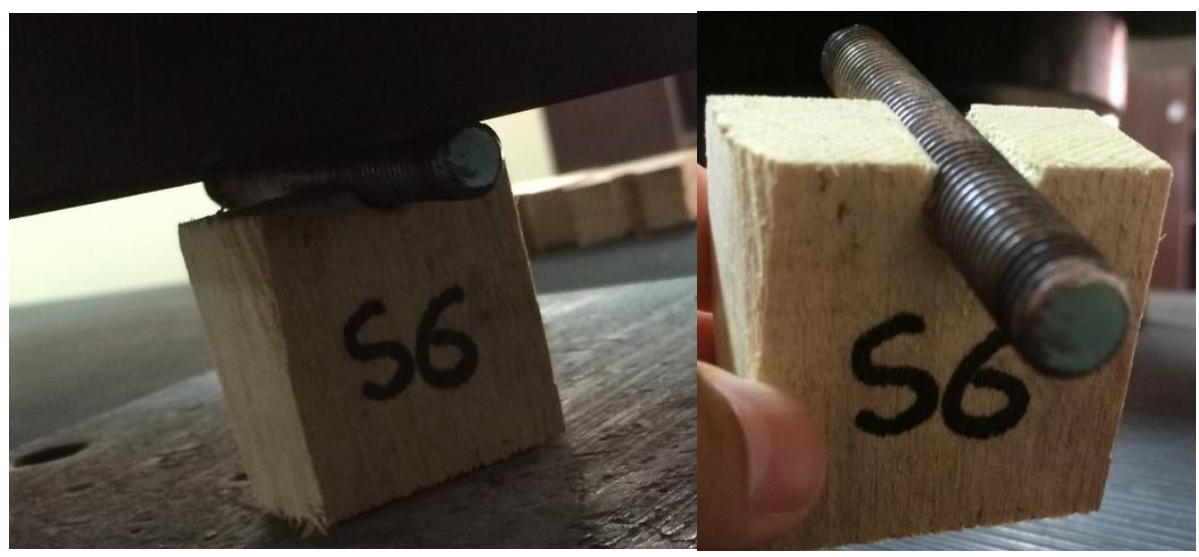

(a)

(b)

Gambar 4. (a) benda Uji saat diberikan beban; (b) kondisi kondisi benda uji setelah pengujian

\section{HASIL DAN PEMBAHASAN}

Melalui hasil pengujian eksperimental didapatkan nilai kurva hubungan beban dan peralihan untuk kayu Sengon, kayu Akasia dan Kayu meranti yang dapat dilihat pada Gambar 5, Gambar 6 dan Gambar 7. Nilai kuat tumpu baut didapatkan dengan membuat garis lurus yang menyingung daerah linier awal pada grafik lalu membuat garis offset sejarak $5 \%$ dari diameter baut yang digunakan, kemudian beban leleh didapatkan dari hasil perpotongan garis offset dengan grafik hubungan beban dan peralihan. Jika garis offset tidak memotong grafik maka beban maksimum yang digunakan sebagai beban leleh.

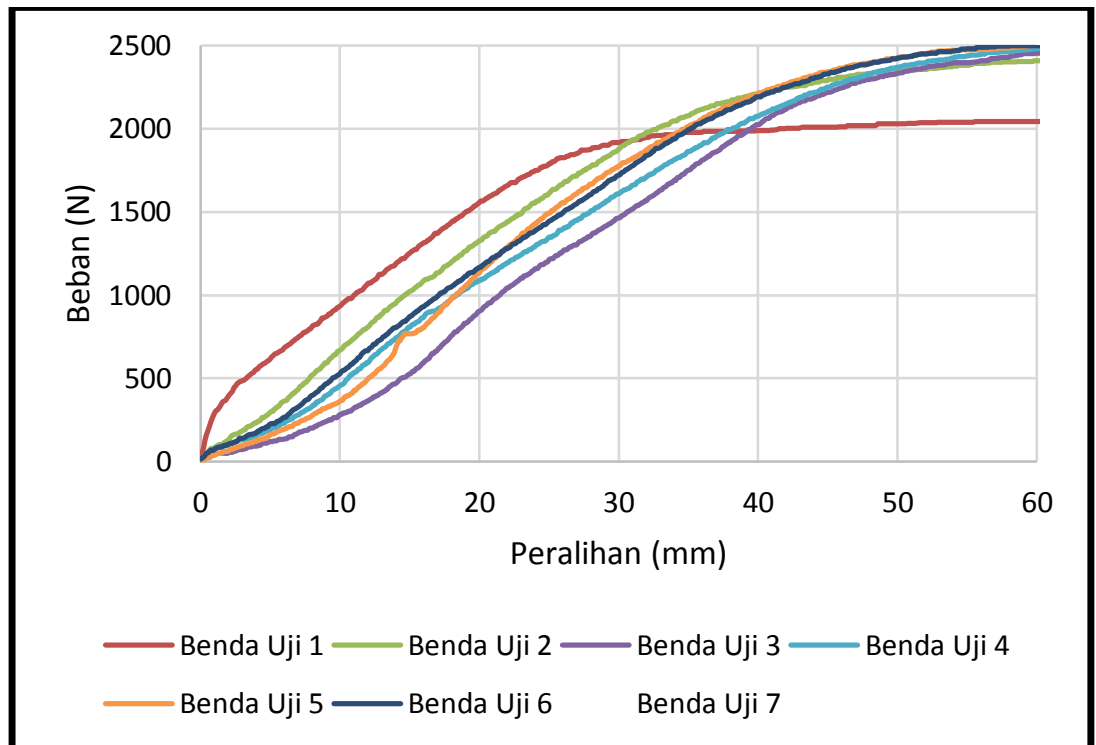

Gambar 5. Kurva peralihan vs beban kayu Sengon 


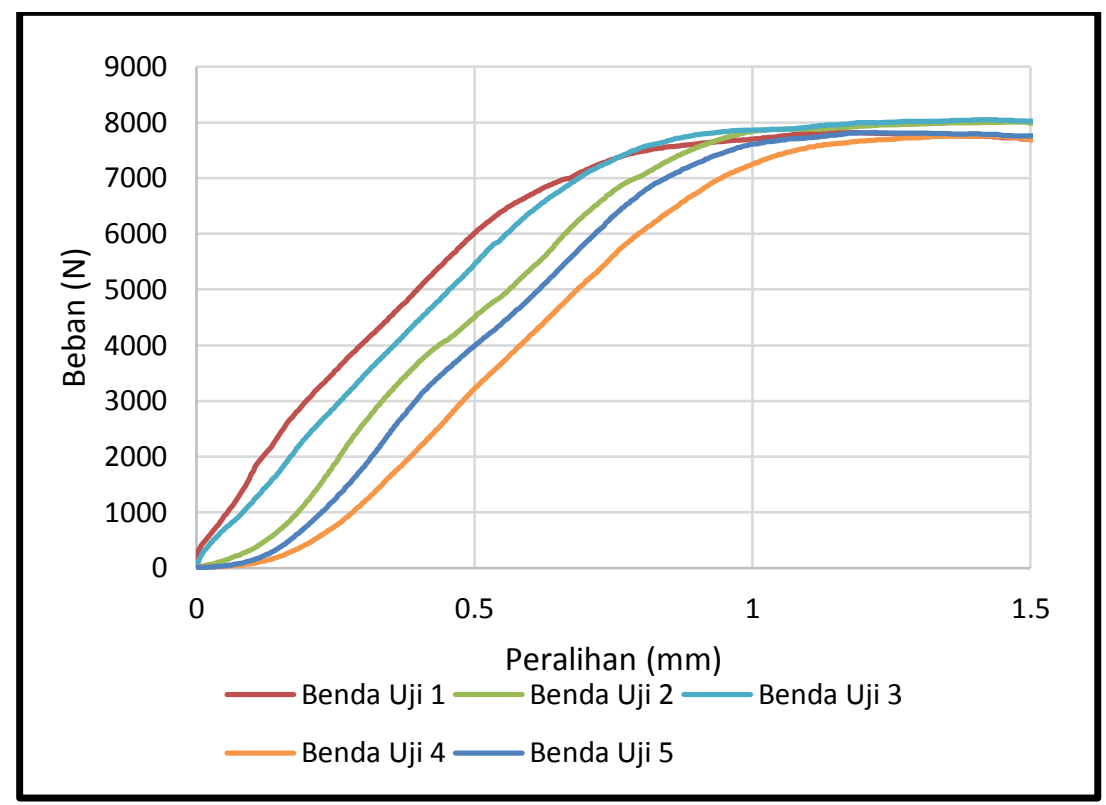

Gambar 6. Kurva peralihan vs beban kayu Akasia

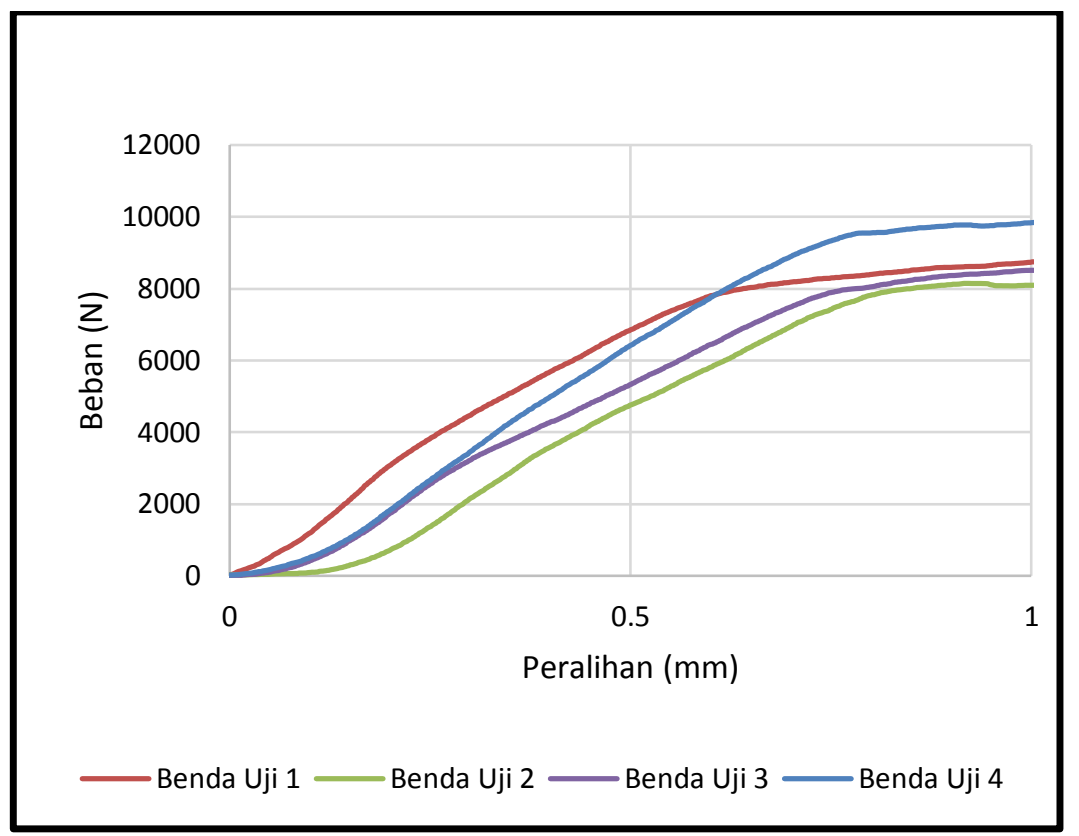

Gambar 7. Kurva peralihan vs beban kayu Meranti

Melalui kurva hubungan beban vs peralihan pada Gambar 5, Gambar 6 dan Gambar 7 didapatkan beban leleh dari masing-masing benda uij. Nilai kuat tumpu pasak dan berat jenis untuk masing-masing benda uji dapat dilihat pada Tabel 1. 
Tabel 1. Kuat Tumpu Pasak Sejajar Serat dan Berat Jenis Berdasarkan Hasil Uji Eksperimental

\begin{tabular}{|c|c|c|c|c|c|c|}
\hline $\begin{array}{l}\text { Jenis } \\
\text { Kayu }\end{array}$ & $\begin{array}{c}\text { No. } \\
\text { Benda } \\
\text { Uji }\end{array}$ & $\begin{array}{c}\text { Tebal } \\
\text { Benda Uji } \\
{[\mathrm{mm}]}\end{array}$ & $\begin{array}{l}P_{5 \%} \\
{[\mathbf{N}]}\end{array}$ & $\begin{array}{c}G \\
{\left[\mathrm{gr} / \mathrm{cm}^{3}\right]}\end{array}$ & $\begin{array}{c}F_{e} \\
{[\mathrm{MPa}]}\end{array}$ & $\begin{array}{c}F_{\text {erata-rata }} \\
\text { Eksperimen } \\
{[\mathrm{MPa}]}\end{array}$ \\
\hline \multirow{7}{*}{ Sengon } & 1 & 20 & 2.000 & 0,35 & 10,00 & \multirow{7}{*}{11,05} \\
\hline & 2 & 20 & 2.100 & 0,32 & 10,50 & \\
\hline & 3 & 20 & 2.200 & 0,31 & 11,00 & \\
\hline & 4 & 19,75 & 2.300 & 0,35 & 11,65 & \\
\hline & 5 & 20 & 2.300 & 0,32 & 11,50 & \\
\hline & 6 & 20,5 & 2.350 & 0,34 & 11,46 & \\
\hline & 7 & 20,5 & 2.300 & 0,34 & 11,22 & \\
\hline \multirow{5}{*}{ Akasia } & 1 & 20,5 & 7.150 & 0,66 & 34,88 & \multirow{5}{*}{37,19} \\
\hline & 2 & 20 & 7.500 & 0,64 & 37,50 & \\
\hline & 3 & 19,5 & 7.450 & 0,62 & 38,21 & \\
\hline & 4 & 19 & 7.300 & 0,68 & 38,42 & \\
\hline & 5 & 19,5 & 7.200 & 0,64 & 36,92 & \\
\hline \multirow{4}{*}{ Meranti } & 1 & 18,5 & 8.200 & 0,68 & 44,32 & \multirow{4}{*}{43,98} \\
\hline & 2 & 19 & 8.100 & 0,66 & 42,63 & \\
\hline & 3 & 20 & 8.150 & 0,62 & 41,79 & \\
\hline & 4 & 19,5 & 9.200 & 0,68 & 47,18 & \\
\hline
\end{tabular}

Tabel 2. Perbandingan Hasil Pengujian Kuat Tumpu Baut Hasil Uji Eksperimental dengan Analisis Teoritis

\begin{tabular}{|c|c|c|c|c|c|c|}
\hline $\begin{array}{l}\text { Jenis } \\
\text { Kayu }\end{array}$ & $\begin{array}{c}\text { No. } \\
\text { Benda } \\
\text { Uji }\end{array}$ & $\underset{\left[\mathrm{gr} / \mathrm{cm}^{3}\right]}{G}$ & $\begin{array}{c}F_{\text {e rata-rata }} \\
\text { Eksperimen } \\
{[\mathrm{MPa}]}\end{array}$ & $\begin{array}{c}F_{e}=70 S G \\
{[\mathrm{MPa}]}\end{array}$ & $\begin{array}{c}F_{\text {erata-rata }} \\
\text { Analisis } \\
\text { [MPa] }\end{array}$ & $\begin{array}{l}\text { Persensi } \\
\text { Beda } \\
{[\%]}\end{array}$ \\
\hline \multirow{7}{*}{ Sengon } & 1 & 0,35 & \multirow{7}{*}{11,05} & 24,50 & \multirow{7}{*}{23,30} & \multirow{7}{*}{52,57} \\
\hline & 2 & 0,32 & & 22,40 & & \\
\hline & 3 & 0,31 & & 21,70 & & \\
\hline & 4 & 0,35 & & 24,50 & & \\
\hline & 5 & 0,32 & & 22,40 & & \\
\hline & 6 & 0,34 & & 23,80 & & \\
\hline & 7 & 0,34 & & 23,80 & & \\
\hline \multirow{5}{*}{ Akasia } & 1 & 0,66 & \multirow{5}{*}{37,19} & 46,20 & \multirow{5}{*}{45,36} & \multirow{5}{*}{18,01} \\
\hline & 2 & 0,64 & & 44,80 & & \\
\hline & 3 & 0,62 & & 43,40 & & \\
\hline & 4 & 0,68 & & 47,60 & & \\
\hline & 5 & 0,64 & & 44,80 & & \\
\hline \multirow{4}{*}{ Meranti } & 1 & 0,68 & \multirow{4}{*}{43,98} & 47,60 & \multirow{4}{*}{46,20} & \multirow{4}{*}{4,80} \\
\hline & 2 & 0,66 & & 46,20 & & \\
\hline & 3 & 0,62 & & 43,40 & & \\
\hline & 4 & 0,68 & & 47,60 & & \\
\hline
\end{tabular}


Melalui hasil pengujian didapatkan berat jenis dari masing-masing benda uji yang kemudian digunakan sebagai parameter menghitung kuat tumpu dengan metode analisis teoritis, berat jenis rata-rata untuk kayu Sengon adalah sebesar 0,33 gr/ $\mathrm{cm}^{3}$; kayu Akasia sebesar 0,65 $\mathrm{gr} / \mathrm{cm}^{3}$; dan kayu Meranti sebesar $0,66 \mathrm{gr} / \mathrm{cm}^{3}$. Melalui hasil perhitungan analisis seperti yang terlihat pada Tabel 2 didapatkan nilai kuat tumpu rata-rata untuk kayu Sengon adalah sebesar 23,30 MPa; kayu Akasia sebesar 45,36 MPa; dan kayu Meranti sebesar 46,20 MPa. Nilai kuat tumpu ekperimental didapatkan dengan cara membagi $P_{5 \%}$ dengan diameter baut dan tebal benda uji, sehingga didapatkan nilai kuat tumpu rata-rata eksperimental untuk kayu Sengon sebesar 11,05 MPa; Akasia sebesar 37,19 MPa; dan Meranti sebesar 43,98 MPa.

\section{KESIMPULAN DAN SARAN}

\subsection{Kesimpulan}

Berdasarkan hasil pengujian eksperimental dan analisis berdasarkan persamaan yang terdapat pada Badan Standardisasi Nasional (2013) dapat disimpulkan bahwa hasil analisis teoritis menghasilkan nilai kuat tumpu baut sejajar serat yang lebih besar dibandingkan dengan hasil pengujian eksperimental. Persensi beda antara pengujian eksperimental dan hasil analisis adalah sebesar 52,57\% untuk kayu Sengon; 18,01\% untuk kayu Akasia; dan 4,80\% untuk kayu Meranti.

\subsection{Saran}

1. Dilakukan penelitian lebih lanjut dengan menggunakan diameter pasak, jenis pasak, jenis kayu dan kemiringan serat yang berbeda.

2. Dilakukan penelitian perbandingan pengaruh antara kuat tumpu pasak dengan benda uji lubang setengah dan lubang penuh.

\section{DAFTAR RUJUKAN}

ASTM D5764-97a. (1997). Standard Test Method for Evaluating Dowel-Bearing Strength of Wood and Wood Based Product. West Conchohocken: ASTM International.

Aune, P. \& Mallory, M. P. (1986). Lateral Load Bearing Capasity of Nailed Joint Based on The Yield Theory. Madison, Winconsin: Forest Product Laboratory, United States Department of Agriculture.

Badan Standardisasi Nasional. (2013). SNI 7973:2013 tentang Spesifikasi Desain Untuk Konstruksi Kayu. Jakarta: Badan Standardisasi Nasional.

Breyer, D. E., Fridley, K. J., Cobeen, K. E. \& Pollock, D. G. (2015). Design of Wood Structure (7 ed.). New York: McGraw-Hill.

Forest Product Laboratory. (1999). Wood Handbook - Wood as Engineering Material. Madison, Winconsin: Forest Product Laboratory, United States Department of Agriculture.

Rammer, D. R. \& Winistorfer, S. G. (1999). Effect of Moisture Content on Dowel-Bearing Strength. Madison, Winconsin: Forest Product Laboratory, United States Department of Agriculture.

Wilkinson, T. (1991). Dowel Bearing Strength. Madison, Winconsin: Forest Product Laboratory, United States Department of Agriculture. 